\title{
Clinical practice and postoperative rehabilitation after knee arthroscopy vary according to surgeons' expertise: a survey among polish arthroscopy society members
}

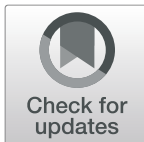

Paweł Bąkowski ${ }^{1 *}$, Kamilla Bąkowska-Żywicka² and Tomasz Piontek ${ }^{1,3}$

\begin{abstract}
Background: Meniscus repair is a challenging task in knee arthroscopy. Currently, there are a variety of arthroscopic methods available for meniscus repair. The purpose of this study was to determine a consensus in meniscus tear treatment in the environment of Polish orthopaedists.

Methods: A total of 205 registered orthopaedic surgeons participated in the surveys. The survey consisted of 35 questions regarding general arthroscopy and postoperative management, including physicians' level of expertise, anaesthesia, postoperative treatment, rehabilitation and procedures performed. Comparisons were made between knee arthroscopy experts (> 100 arthroscopies performed per year) and non-experts ( $\leq 100$ cases) on aspects of patient care.

Results: The most important finding of this study was the agreement among almost all aspects of the knee arthroscopy approach. Consensus among Polish surgeons was noticed in choosing regional anaesthesia for knee arthroscopy, the lack of need for knee braces and knee medications, the of use of LMW heparin for thromboprophylaxis, 1-2 days of hospitalization, the recommendation of rehabilitation and the use of magnetic resonance as a diagnostic test for meniscus damage. Surgical expertise was significantly associated with the performance of meniscus suture procedures $(p=0.009)$. Experts recommended starting rehabilitation on the day of surgery $(p=0.007)$ and were more likely to use objective physical tests $(p=0.003)$. Non-expert surgeons recommended a longer period from meniscus suture to full-range knee motion $(p=0.001)$ and admitted that patient age does matter for meniscus repair qualification ( $p=0.002$ ).

Conclusions: There is consensus among almost all issues of meniscus tear treatment in the environment of Polish orthopaedists; however, the issues of rehabilitation and the use of advanced meniscus repair techniques are associated with surgical expertise.
\end{abstract}

Keywords: Knee arthroscopy, Meniscus repair, Survey, Surgical expertise, Rehabilitation, Return to sport

* Correspondence: pawel.bakowski@rehasport.pl

'Department of Orthopedic Surgery, Rehasport Clinic, Górecka Street 30, 60201 Poznan, Poland

Full list of author information is available at the end of the article

(c) The Author(s). 2020 Open Access This article is licensed under a Creative Commons Attribution 4.0 International License, which permits use, sharing, adaptation, distribution and reproduction in any medium or format, as long as you give appropriate credit to the original author(s) and the source, provide a link to the Creative Commons licence, and indicate if changes were made. The images or other third party material in this article are included in the article's Creative Commons licence, unless indicated otherwise in a credit line to the material. If material is not included in the article's Creative Commons licence and your intended use is not permitted by statutory regulation or exceeds the permitted use, you will need to obtain permission directly from the copyright holder. To view a copy of this licence, visit http://creativecommons.org/licenses/by/4.0/ The Creative Commons Public Domain Dedication waiver (http://creativecommons.org/publicdomain/zero/1.0/) applies to the data made available in this article, unless otherwise stated in a credit line to the data. 


\section{Background}

Meniscus injuries represent a common ailment of knee damage [1]. Due to the hypovascularity and hypocellularity of the meniscus, meniscus tears do not heal spontaneously [2-4], and prolonged untreated damage may lead to the development of osteoarthritis [5-7]. Current orthopaedic practice aims to preserve meniscal integrity and restore function [8-11]. A variety of arthroscopic methods of meniscus repair are used, including different suturing techniques, which are often modified to increase effectiveness [12-15]. Therefore, studies aimed at the analysis of existing meniscus repair methods are very important. Recently, the European Society for Sports Traumatology, Knee Surgery and Arthroscopy (ESSKA) consensus provided recommendations for the treatment of meniscus tears based on both scientific evidence and the clinical experience of expert knee surgeons [16, 17]. Other studies have shown that a surgeon's level of expertise significantly affects clinical outcomes in patients undergoing knee arthroscopy $[18,19]$. Therefore, the main goal of the study was to determine a consensus in meniscus tear treatment in the environment of Polish orthopaedists. We hypothesized that clinical practice would differ among the Polish Arthroscopy Society community members according to the level of surgical expertise.

\section{Methods}

For this study, a questionnaire was presented to 205 orthopaedists with various levels of clinical expertise in arthroscopy during the Polish Arthroscopy Society Congress, which was held on 24-26 October 2019 in Katowice, Poland. The questionnaire consisted of six sections with a total of 35 questions regarding knee arthroscopy and postoperative management. The six sections of the questionnaire were as follows: (A) the physician's level of expertise (4 questions), (B) anaesthesia during arthroscopy (1 question), (C) postoperative treatment (3 questions), (D) hospital stay (3 questions), (E) rehabilitation protocols (11 questions) and (F) procedures in arthroscopy (13 questions). The complete survey is available in Additional file 1.

A pilot survey was conducted before the meeting. The questionnaire was distributed to 10 orthopaedic surgeons and a biostatistician to ensure that it was scientifically sound and that the question stems were easy to understand. We defined experts as any participating orthopaedist who had performed $>100$ knee arthroscopies per year. Orthopaedists who had performed 100 or fewer knee arthroscopies per year were classified as nonexperts for this study.

\section{Statistical analysis}

Statistics were conducted using Prism8 software (GraphPad Software, San Diego, CA). Power analysis was conducted to identify the minimum number of participants required in each group to detect statistical significance. The sample size calculation showed that with a power of $80 \%$ (2-sided testing at a significance level of 0.05), a sample size of 43 participants was needed. To test proportional differences in categorical variables, a Chisquare test was performed. Fisher's exact test was used when cells contained less than five subjects. Statistical significance was determined at $p<0.05$.

\section{Results}

A total of 205 participants received questionnaires. All survey forms were used for the analysis. Table 1 presents the educational background of the participating surgeons in the field of knee arthroscopy. Fifty-five orthopaedists (28\%) performed more than 100 knee arthroscopies per year independently and were classified as experts for this study. The remaining 150 orthopaedists (72\%) performed up to 100 knee arthroscopies per year and were therefore classified as non-experts.

The comparison of the clinical practice between expert and non-expert surgeons who performed knee arthroscopy is shown in Table 2. Regional anaesthesia (spinal/ epidural) was favoured by $172(84 \%)$ orthopaedists (48 experts and 124 non-experts). Only 27 (13\%) orthopaedists (4 experts and 23 non-experts) recommended the use of an orthosis to their patients immediately after knee arthroscopy. Only $22(10 \%)$ orthopaedists (8 experts and 10 non-experts) used knee medications in the first $24 \mathrm{~h}$ after arthroscopy. The most commonly reported pain medications were local anaesthetic drugs belonging to the amino amide group (8 surgeons) or hyaluronic acid (7 surgeons). Experts and non-experts answered almost equally when asked about antithrombotic prophylaxis administered to patients. Lowmolecular-weight heparin (LMH) was recommended by 181 (88\%) surgeons (51 experts and 130 non-experts). Both knee arthroscopy experts (85\%) and non-experts (75\%) recommended 1 day of hospitalization after nonreconstructive arthroscopy. One or 2 days of hospitalization were most frequently recommended after reconstructive arthroscopy.

The comparison of the rehabilitation recommendations is shown in Table 3. A total of 203 (99\%) surgeons (55 experts and 148 non-experts) reported that they always discussed the importance of rehabilitation with the patients. A total of 135 (64\%) surgeons always recommend rehabilitation (excluding physical therapy), and 43 (21\%) mostly recommend rehabilitation. There was a statistically significant difference $(p=0.032)$ when surgeons were asked about their patients' compliance with the rehabilitation recommendations. A total of $22 \%$ of experts and $14 \%$ of non-experts admitted that their patients mostly followed the rehabilitation recommendations. A total of 124 (60\%) surgeons recommended 
Table 1 Physician's level of education and experience

\begin{tabular}{|c|c|c|}
\hline Parameter: & Parameter value: & Surgeons $(n=205)$ \\
\hline \multirow[t]{3}{*}{ Participation in the knee arthroscopy during residency or specialization } & 0 & $8(4 \%)$ \\
\hline & $1-30$ & $28(14 \%)$ \\
\hline & $>30$ & $169(82 \%)$ \\
\hline \multirow[t]{3}{*}{ The independent knee arthroscopies performed per year } & $0-50$ & $98(47 \%)$ \\
\hline & $50-100$ & $52(25 \%)$ \\
\hline & $>100$ & $55(28 \%)$ \\
\hline \multirow[t]{2}{*}{ The independent knee arthroscopies performed during career } & $0-500$ & $127(62 \%)$ \\
\hline & $>500$ & $78(38 \%)$ \\
\hline \multirow[t]{7}{*}{ The joints currently subjected to arthroscopy procedures } & shoulder & $83(41 \%)$ \\
\hline & elbow & $28(14 \%)$ \\
\hline & wrist & $9(4 \%)$ \\
\hline & spine & $1(0.5 \%)$ \\
\hline & hip & $41(20 \%)$ \\
\hline & knee & $200(98 \%)$ \\
\hline & ankle & $82(40 \%)$ \\
\hline
\end{tabular}

beginning rehabilitation within 1 day after surgery. Knee arthroscopy experts more frequently recommended beginning rehabilitation on the day of surgery (14 of 55 experts, 25\%, $p=0.007)$. A standardized rehabilitation protocol was recommended by 84 (42\%) surgeons. A total of $176(86 \%)$ surgeons reported that the rehabilitation protocol was dependent on the procedure performed. A total of 189 (92\%) surgeons reported that the physical therapist was the key person responsible for patient rehabilitation. Cryotherapy was recommended by $77 \%$ of orthopaedists (42 experts and 113 non-experts) and physical therapy by $65 \%$. Within this group, laser therapy and magnetotherapy were most frequently used.

Table 4 shows the factors considered when recommending return to sport activity after knee arthroscopy. In most cases, either the surgeon alone or the surgeon together with a physical therapist were responsible for the decision of whether a patient was ready to return to sport. The most important factor in the decision process was the functional state of the patient (93\% of experts and $74 \%$ non-experts, $p=0.002)$. Objective measurements were used to aid in the decision of whether to return to sport by 159 (78\%) surgeons (50 experts and 109 non-experts, $p=0.003)$. Among them, functional tests were preferred by experts $(p=0.006)$.

The comparison of the knee arthroscopic procedures performed by expert and non-expert surgeons is shown in Table 5. Both experts and non-experts used a broad spectrum of arthroscopic procedures (Fig. 1). Nonexperts had significantly less experience with meniscus suturing $(p=0.005)$ and more experience with meniscus removal $(p=0.009)$ (Fig. 2). Experts used significantly more meniscus repair techniques than non-experts (Fig. 3). The diagnostic tests used by experts and nonexperts were similar (n.s.), with magnetic resonance being the preferred diagnostic method (Fig. 4).

The comparison of the post-arthroscopic procedures performed by expert and non-expert surgeons is shown

Table 2 Comparison of the clinical practice between expert and non-expert surgeons who perform knee arthroscopy

\begin{tabular}{|c|c|c|c|c|}
\hline Parameter: & $\begin{array}{l}\text { All } \\
(n=205)\end{array}$ & $\begin{array}{l}\text { Experts } \\
(n=55)\end{array}$ & $\begin{array}{l}\text { Non-experts } \\
(n=150)\end{array}$ & $p$ value \\
\hline Use of regional anesthesia & $172(84 \%)$ & $48(87 \%)$ & $124(83 \%)$ & n.s. \\
\hline Recommend orthosis & $27(13 \%)$ & $4(7 \%)$ & $23(15 \%)$ & n.s. \\
\hline Use of a knee drain & $189(92 \%)$ & $50(91 \%)$ & $139(72 \%)$ & 0.012 \\
\hline Use of knee medications & $22(10 \%)$ & $8(15 \%)$ & $10(7 \%)$ & n.s. \\
\hline Recommend LMW as thromboprophylaxis & $181(88 \%)$ & $51(94 \%)$ & $130(87 \%)$ & n.s. \\
\hline One day hospitalization after non-reconstructive arthroscopy & $160(77 \%)$ & $47(85 \%)$ & $113(75 \%)$ & n.s. \\
\hline One day of hospitalization after reconstructive arthroscopy & $81(39 \%)$ & $29(52 \%)$ & $52(35 \%)$ & n.s. \\
\hline Two days of hospitalization after reconstructive arthroscopy & $90(44 \%)$ & $17(31 \%)$ & $73(49 \%)$ & n.s. \\
\hline
\end{tabular}

$p$ value is presented to establish statistical significance between expert and non-expert treatment. n.s. not significant, LMW heparin low molecular weight heparin 
Table 3 Comparison of post-surgical rehabilitation recommendations between expert and non-expert surgeons who perform knee arthroscopy

\begin{tabular}{|c|c|c|c|c|}
\hline Parameter: & All $(n=205)$ & Experts $(n=55)$ & Non-experts $(n=150)$ & $p$ value \\
\hline Talk about the need for rehabilitation & $203(99 \%)$ & $55(100 \%)$ & $148(99 \%)$ & n.s. \\
\hline Always recommend rehabilitation & $135(64 \%)$ & $41(75 \%)$ & $94(63 \%)$ & n.s. \\
\hline Mostly recommend rehabilitation & $43(21 \%)$ & $8(14 \%)$ & $35(23 \%)$ & n.s. \\
\hline Patients mostly follow the rehabilitation recommendations & $28(14 \%)$ & $12(22 \%)$ & $16(14 \%)$ & 0.032 \\
\hline Patients sometimes follow the rehabilitation recommendations & $122(60 \%)$ & $30(55 \%)$ & $92(61 \%)$ & n.s. \\
\hline Beginning of rehabilitation on the day of surgery & $22(11 \%)$ & $14(25 \%)$ & $8(5 \%)$ & 0.007 \\
\hline Beginning of rehabilitation one day after the surgery & $124(60 \%)$ & $33(60 \%)$ & $91(61 \%)$ & \\
\hline Recommend standardized rehabilitation & $84(42 \%)$ & $21(38 \%)$ & $63(43 \%)$ & n.s. \\
\hline Dependence of rehabilitation program on performed procedure & $176(86 \%)$ & $47(85 \%)$ & $129(63 \%)$ & n.s. \\
\hline Recommend rehabilitation with a physiotherapist & $189(92 \%)$ & $49(89 \%)$ & 140 (93\%) & n.s. \\
\hline Recommend cryotherapy & $158(77 \%)$ & $45(82 \%)$ & $113(75 \%)$ & n.s. \\
\hline Recommend physical therapy & $133(65 \%)$ & $29(53 \%)$ & $104(69 \%)$ & 0.04 \\
\hline Recommend lasertherapy & $69(34 \%)$ & $16(29 \%)$ & $53(35 \%)$ & n.s. \\
\hline Recommend magnetotherapy & $71(34 \%)$ & $7(13 \%)$ & $51(34 \%)$ & n.s. \\
\hline Recommend ultrasounds & $58(28 \%)$ & $18(32 \%)$ & $53(35 \%)$ & n.s. \\
\hline Recommend ionophoresis & $39(19 \%)$ & $8(14 \%)$ & $31(20 \%)$ & n.s. \\
\hline Recommend TENS & $38(19 \%)$ & $7(13 \%)$ & $31(20 \%)$ & n.s. \\
\hline
\end{tabular}

$p$ value is presented to establish statistical significance between expert and non-expert treatment. n.s. not significant

in Table 6. Both experts and non-experts recommended similar times of elbow crutch use after meniscus removal ( 2 weeks) or orthosis after meniscus suturing (6 weeks). However, the answers were different when surgeons were asked about how soon after meniscus suturing they recommended full range of knee motion. Experts recommended 4 weeks, and non-experts recommended 6 weeks $(p=0.001)$.

The comparison of the factors influencing the decision of arthroscopic procedures between expert and nonexpert surgeons is shown in Table 7. Experts and nonexperts named similar factors when they considered whether to remove or repair the meniscus - damage type, damage zone and patient age. However, in regard to meniscus repair qualifications, experts stated that age did not matter significantly more frequently than nonexperts $(p=0.002)$.

At the end of the survey, the participating orthopaedists were asked to choose the recommended procedure for traumatic meniscus tears in 18-year-old and 30-yearold professional football players. A total of 179 (87\%) orthopaedists decided to repair the damaged part of the meniscus in an 18-year-old patient: 53 (97\%) experts and $126(84 \%)$ non-experts. A total of $166(81 \%)$ surgeons

Table 4 Comparison of return to sport recommendations between expert and non-expert surgeons who perform knee arthroscopy

\begin{tabular}{|c|c|c|c|c|}
\hline Parameter: & All $(n=205)$ & Experts $(n=55)$ & Non-experts $(n=150)$ & $p$ value \\
\hline Decision by surgeon & $77(37 \%)$ & $23(45 \%)$ & $54(36 \%)$ & n.s. \\
\hline Decision by surgeon and physical therapist & $87(42 \%)$ & $30(54 \%)$ & $57(38 \%)$ & n.s. \\
\hline Functional state as a decisive criterion & $162(80 \%)$ & $51(93 \%)$ & $111(74 \%)$ & 0.002 \\
\hline Lack of discomfort as a decisive criterion & $86(42 \%)$ & 19 (34\%) & $67(45 \%)$ & n.s. \\
\hline Time since arthroscopy as a decisive criterion & $72(35 \%)$ & $24(44 \%)$ & $48(32 \%)$ & n.s. \\
\hline Correct image in examination as a decisive criterion & $39(19 \%)$ & $12(22 \%)$ & $27(18 \%)$ & n.s. \\
\hline Use of objective physical tests & $159(78 \%)$ & $50(91 \%)$ & $109(66 \%)$ & 0.003 \\
\hline Use of functional tests & $119(58 \%)$ & $44(80 \%)$ & $75(50 \%)$ & 0.006 \\
\hline Use of dynamometer & $58(28 \%)$ & $22(40 \%)$ & $36(24 \%)$ & n.s. \\
\hline Use of subjective surveys & 35 (17\%) & $11(20 \%)$ & $24(16 \%)$ & n.s. \\
\hline
\end{tabular}

$p$ value is presented to establish statistical significance between expert and non-expert treatment. n.s. not significant 
Table 5 Comparison of knee arthroscopic procedures performed by expert and non-expert surgeons

\begin{tabular}{|c|c|c|c|c|}
\hline Parameter: & All $(n=205)$ & Experts $(n=55)$ & Non-experts $(n=150)$ & $p$ value \\
\hline \multicolumn{5}{|l|}{ KNEE ARTHROSCOPY PROCEDURES USED: } \\
\hline ACL reconstruction & $177(86 \%)$ & $55(100 \%)$ & $122(81 \%)$ & 0.003 \\
\hline Meniscus removal & $173(84 \%)$ & $51(93 \%)$ & $122(81 \%)$ & n.s. \\
\hline Meniscus suturing all inside & $171(83 \%)$ & $53(96 \%)$ & $118(79 \%)$ & n.s. \\
\hline Synovial folds removal & $164(80 \%)$ & $40(73 \%)$ & $124(83 \%)$ & n.s. \\
\hline Meniscus suturing inside-out/outside-in & $161(79 \%)$ & $48(87 \%)$ & $113(75 \%)$ & n.s. \\
\hline Microfractures & $170(83 \%)$ & $49(89 \%)$ & $121(81 \%)$ & n.s. \\
\hline Diagnostic arthroscopy & $119(58 \%)$ & $25(45 \%)$ & $94(63 \%)$ & $<0.001$ \\
\hline Cartilage reconstruction & $99(48 \%)$ & $41(75 \%)$ & $58(39 \%)$ & $<0.001$ \\
\hline Simultaneous multi-ligament reconstruction & $76(37 \%)$ & $33(60 \%)$ & $43(29 \%)$ & $<0.001$ \\
\hline PCL reconstruction & $66(32 \%)$ & $32(58 \%)$ & $34(23 \%)$ & $<0.001$ \\
\hline Ramp lesion repair & $66(32 \%)$ & $30(55 \%)$ & $36(24 \%)$ & 0.004 \\
\hline Pediatric multi-ligament reconstruction & $36(18 \%)$ & $18(33 \%)$ & $18(12 \%)$ & 0.004 \\
\hline Meniscus transplant & $32(16 \%)$ & $17(31 \%)$ & $15(10 \%)$ & $<0.001$ \\
\hline \multicolumn{5}{|c|}{ KNEE ARTHROSCOPY PROCEDURES USED MOST FREQUENTLY: } \\
\hline Meniscus removal & $47(23 \%)$ & $10(18 \%)$ & $37(25 \%)$ & 0.009 \\
\hline Meniscus suturing & $45(22 \%)$ & $21(38 \%)$ & $25(17 \%)$ & 0.005 \\
\hline ACL reconstruction & $44(21 \%)$ & $9(16 \%)$ & $35(23 \%)$ & n.s. \\
\hline \multicolumn{5}{|l|}{ MENISCUS REPAIR METHODS USED } \\
\hline Suturing all inside & $164(80 \%)$ & $47(85 \%)$ & $117(78 \%)$ & 0.009 \\
\hline Suturing inside-out & $132(64 \%)$ & $44(80 \%)$ & $88(59 \%)$ & 0.006 \\
\hline Suturing outside-out & $105(51 \%)$ & $34(62 \%)$ & $71(47 \%)$ & 0.006 \\
\hline Scarification & $68(33 \%)$ & $21(38 \%)$ & $47(31 \%)$ & n.s. \\
\hline Platelet rich plasma & $48(23 \%)$ & $19(35 \%)$ & $29(19 \%)$ & 0.009 \\
\hline Bone marrow cells & $13(6 \%)$ & $11(20 \%)$ & $2(1 \%)$ & $<0.001$ \\
\hline Biomaterials & $12(6 \%)$ & $7(13 \%)$ & $5(3 \%)$ & $<0.001$ \\
\hline Autologous adipose tissue & $6(3 \%)$ & $4(7 \%)$ & $2(1 \%)$ & $<0.001$ \\
\hline \multicolumn{5}{|l|}{ DIAGNOSTIC TESTS USED: } \\
\hline Magnetic resonance & $200(98 \%)$ & $54(98 \%)$ & $146(97 \%)$ & n.s. \\
\hline Ultrasonogram & $101(49 \%)$ & $28(51 \%)$ & $73(49 \%)$ & n.s. \\
\hline X-ray & $28(14 \%)$ & $7(13 \%)$ & $21(14 \%)$ & n.s. \\
\hline
\end{tabular}

$p$ value is presented to establish statistical significance between expert and non-expert treatment. $n$.s. not significant

decided to repair the damaged part of the meniscus in a 30-year-old patient: 44 (80\%) experts and $122(81 \%)$ non-experts.

\section{Discussion}

The most important finding of the present study was the agreement between expert and non-expert arthroscopic knee surgeons in most aspects of clinical care. This survey explored numerous aspects of the perioperative and postoperative care of patients undergoing knee arthroscopy.

A consensus among Polish orthopaedists was reached in the preferential use of regional anaesthesia for knee arthroscopy. This is in agreement with world standards [20-23]. Regional anaesthesia, in contrast to general anaesthesia, is a simple, safe technique that is well accepted by patients and reduces the length of hospital stay. Therefore, experts and non-experts agreed on the short duration of hospital stay after knee arthroscopy (1-2 days). Polish surgeons also agreed on the lack of need for the routine recommendation of using a knee orthosis, which is in agreement with previous studies, showing no beneficial effect of bracing after knee arthroscopy $[24,25]$ or even indirect prevention of ACL re-rupture in cases of rehabilitation without a knee brace [26]. 


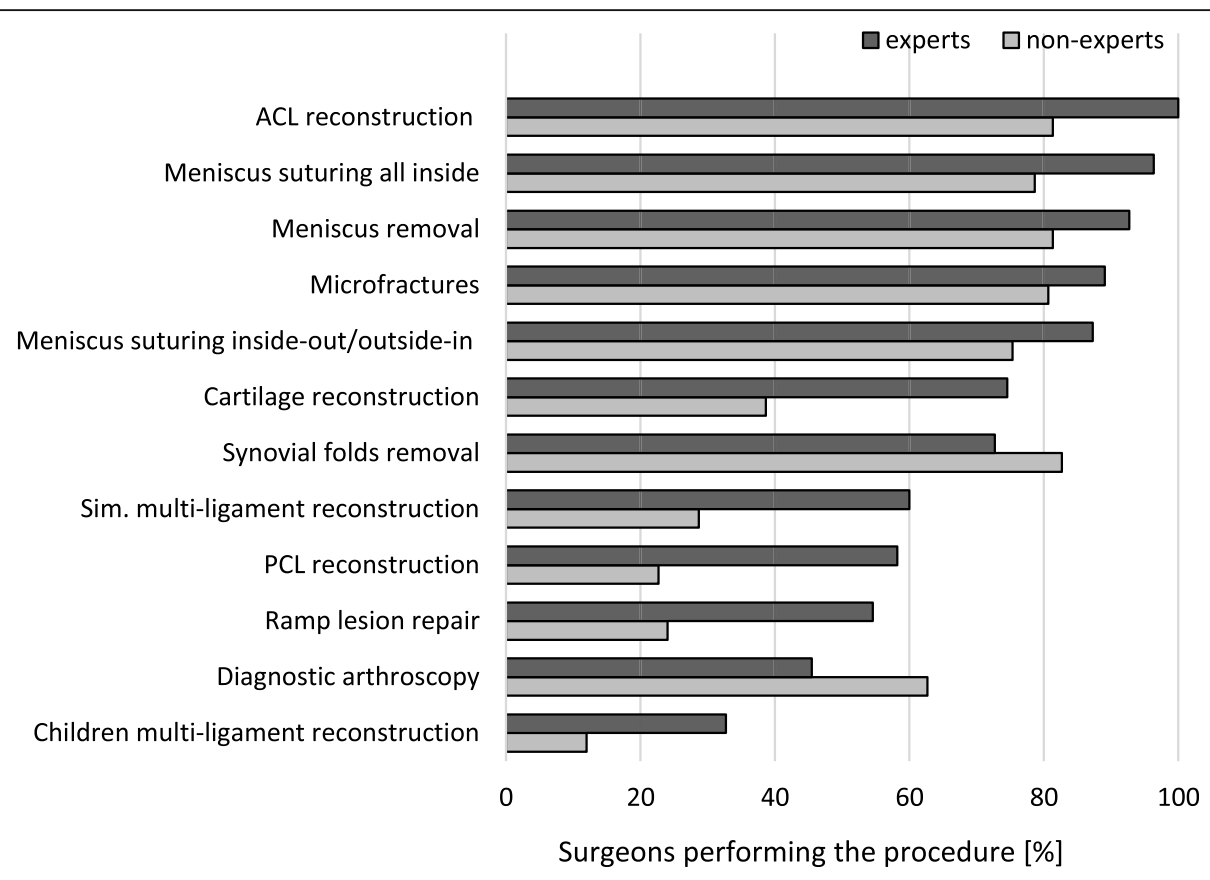

Fig. 1 Procedures performed by the participating surgeons

Pain control after knee arthroscopy is an important aspect of the patient experience. In this survey, all surgeons agreed that there is no need for intraarticular knee medications immediately after knee arthroscopy. This did not differ between the expert and non-expert surgeons. The presentation of pain is determined by the procedure of knee surgery, and previous studies have shown that a significant proportion of patients have only very mild or mild pain after knee arthroscopic procedures [27].

The current guidelines for thromboprophylaxis recommend the use of vitamin $\mathrm{K}$ antagonists (e.g., warfarin),

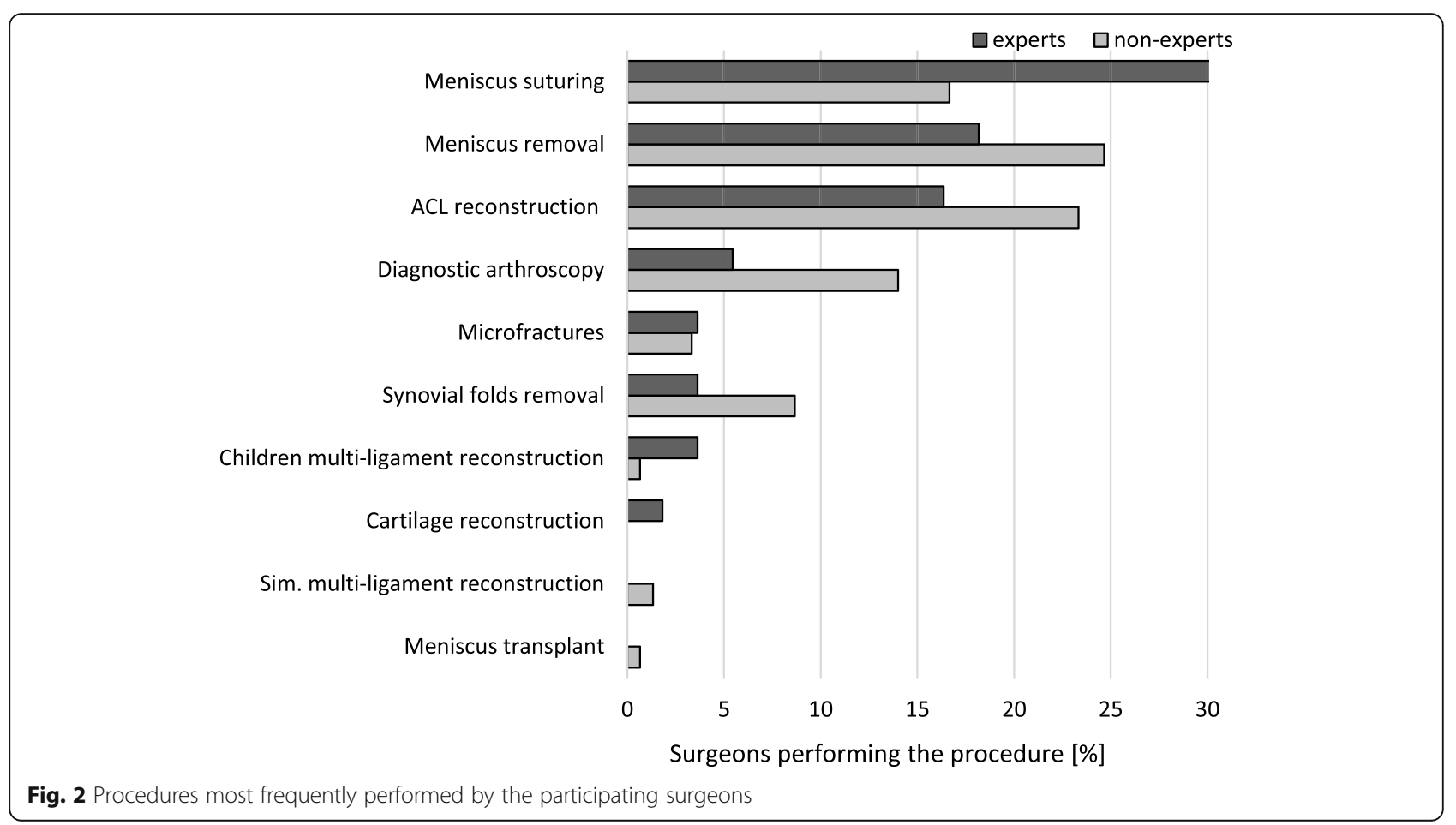




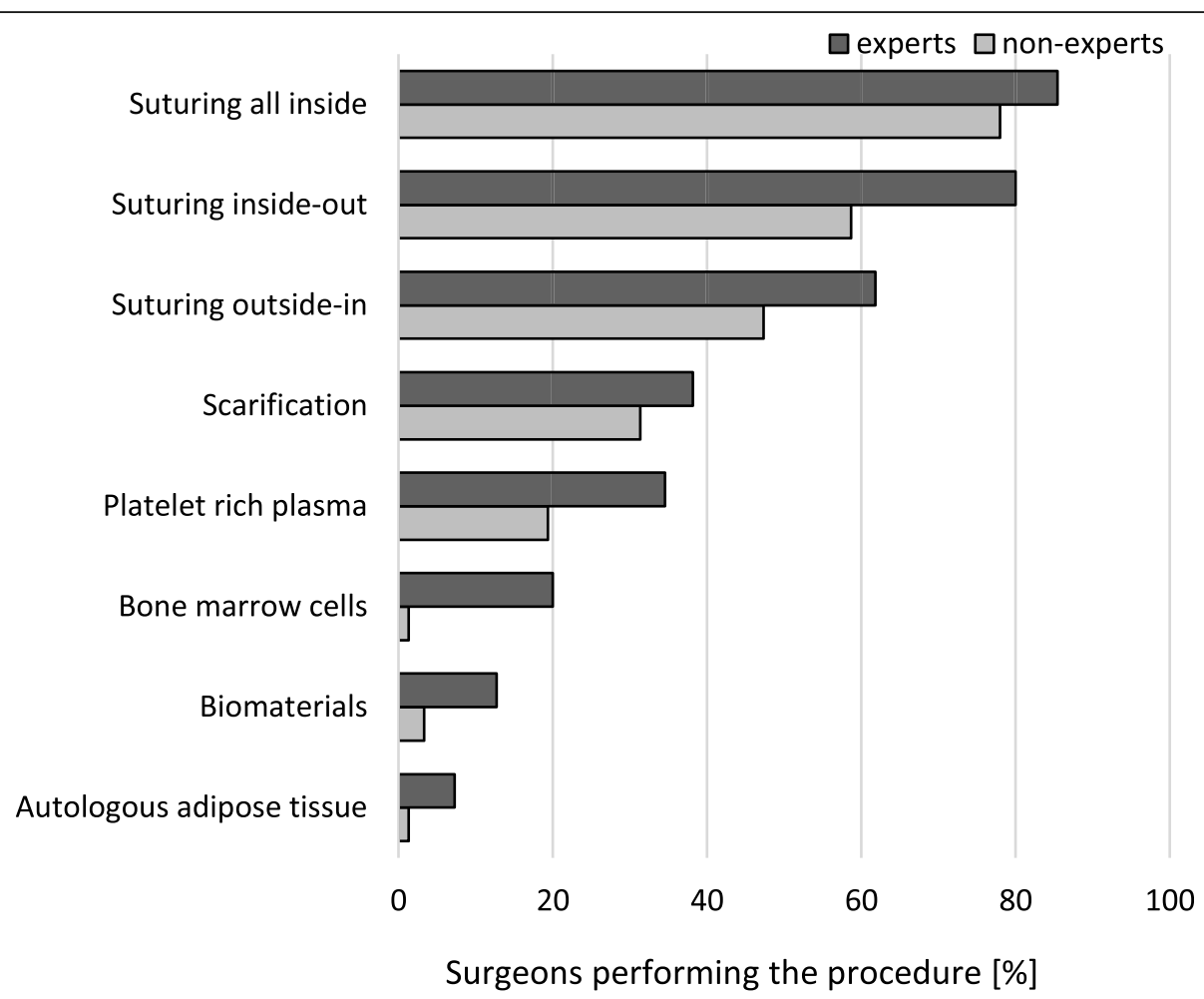

Fig. 3 Meniscus repair methods performed by the participating surgeons

low-molecular-weight heparins (LMW heparin) or aspirin [28-30]. Polish experts and non-experts agreed on the use of LMW heparin, following the recommendations regarding venous thromboembolism prevention in orthopaedic surgery and traumatology developed by Polish orthopaedic surgery experts under the auspices of the National Consultant for Orthopaedic Surgery and
Traumatology and the chairman of the Polish Society for Orthopaedic Surgery and Traumatology [31].

Postoperative rehabilitation is crucial to achieve successful outcomes in patients undergoing knee arthroscopy [32], and the role of the surgeon is to educate patients about its importance. Polish surgeons agreed that proper postoperative rehabilitation of the knee is

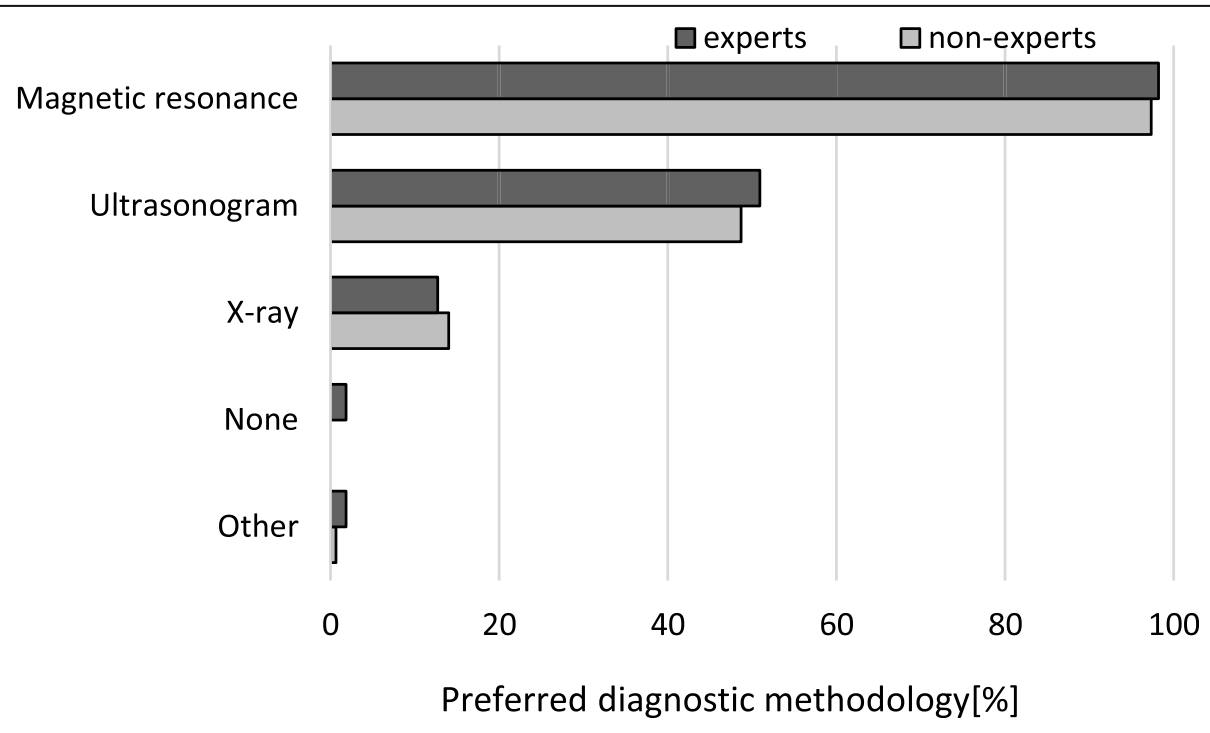

Fig. 4 Diagnostic methods used by the participating surgeons 
Table 6 Comparison of post-arthroscopic procedures performed by expert and non-expert surgeons

\begin{tabular}{lllll}
\hline Parameter: & All $(\boldsymbol{n = 2 0 5 )}$ & Experts $(\boldsymbol{n = 5 5 )}$ & Non-experts $(\boldsymbol{n}=\mathbf{1 5 0})$ & $\boldsymbol{p}$ value \\
\hline Recommend using elbow crutches for 2 weeks & $57(28 \%)$ & $13(24 \%)$ & $54(36 \%)$ & n.s. \\
Recommend using elbow crutches for 1-6 days & $34(17 \%)$ & $11(20 \%)$ & $23(15 \%)$ & n.s. \\
Recommend using orthosis for 6 weeks & $70(34 \%)$ & $19(35 \%)$ & $19 \%)$ & n.s. \\
Recommend a full range of knee motion after 6 weeks & $79(39 \%)$ & $19(34 \%)$ & $30 \%)$ & 0.001 \\
Recommend a full range of knee motion after 4 weeks & $48(24 \%)$ & $18(33 \%)$ & $30 \%)$ & 0.001 \\
\hline
\end{tabular}

$p$ value is presented to establish statistical significance between expert and non-expert treatment. n.s. not significant

essential for returning to an active lifestyle. In our survey, $99 \%$ of the surgeons reported that they discussed the importance of compliance with the rehabilitation protocol with the patient. However, there is still room for improvement, since $1 \%$ of surgeons never recommend rehabilitation, 5\% - rarely and 7\% - only sometimes. In contrast to non-experts, experts admitted that their patients comply with the rehabilitation protocol to a high extent. This might be explained by the greater authority of more experienced surgeons. Polish experts recommended starting rehabilitation on the day of surgery. Surgeons from all over the world have increasingly emphasized early mobilization, which may produce favourable postoperative outcomes [33-35]. Most surgeons (92\%) reported that they always recommended that their patient undergo rehabilitation with a physiotherapist after knee arthroscopy, which is now considered the gold standard, and its effectiveness has been shown by a number of control studies [36-39]. Expert surgeons did not use physical therapists as much as non-experts in making a decision regarding returning to activity. This may be due to newer surgeons being more conservative, relying on physical therapists for another opinion. Evidence-based medicine (EBM) does not exist in physical therapy, in contrast to physiotherapy. In this survey, experts and non-experts recommended physical therapy less frequently (65\%) than rehabilitation with a physiotherapist (92\%). More research is needed, and consensus should be determined by the Polish National Health Fund in terms of the recommendations of physical therapy after knee arthroscopy.

There is a lack of consensus regarding the optimal postoperative protocol following meniscus repair [32]. Diverse treatment methods require individual and various rehabilitation approaches, which is why direct cooperation between the physiotherapist and the patient is so important [40]. Only $42 \%$ of Polish surgeons recommend standardized rehabilitation, and $86 \%$ confirm the dependence of the rehabilitation programme on the performed procedure. Additional studies are needed to better clarify the interplay among the tear type, repair method and optimal rehabilitation protocol.

Magnetic resonance imaging (MRI) is considered to be the most accurate method for imaging the internal knee joint structure, with sensitivities in detecting medial meniscus lesions ranging from 83 to $94 \%$ [41-43]. The ESSKA meniscus consensus group recommended MRI when arthroscopy is considered to identify concomitant

Table 7 Comparison of the factors influencing the decision on arthroscopic procedures between expert and non-expert surgeons

\begin{tabular}{|c|c|c|c|c|}
\hline Parameter: & All $(n=205)$ & Experts $(n=55)$ & Non-experts $(n=150)$ & $p$ value \\
\hline \multicolumn{5}{|c|}{ FACTORS INFLUENCING THE REMOVE/REPAIR DECISION: } \\
\hline Damage type & $175(85 \%)$ & $50(91 \%)$ & $125(83 \%)$ & n.s. \\
\hline Damage zone & $167(76 \%)$ & $46(84 \%)$ & $121(82 \%)$ & n.s. \\
\hline Patient's age & $151(74 \%)$ & $37(67 \%)$ & $114(76 \%)$ & n.s. \\
\hline Time since injury & $118(58 \%)$ & $30(54 \%)$ & $88(59 \%)$ & n.s. \\
\hline Physical activity & $105(51 \%)$ & $24(44 \%)$ & $81(54 \%)$ & n.s. \\
\hline Accompanying damage & $44(23 \%)$ & $14(25 \%)$ & $30(20 \%)$ & n.s. \\
\hline Damage representation in magnetic resonance & $75(36 \%)$ & $22(40 \%)$ & $53(35 \%)$ & n.s. \\
\hline Sport discipline practiced by the patient & $103(50 \%)$ & $23(42 \%)$ & $80(54 \%)$ & n.s. \\
\hline \multicolumn{5}{|c|}{ PATIENT'S AGE INFLUENCE ON MENISCUS REPAIR QUALIFICATION: } \\
\hline Less than 50 years old & $45(22 \%)$ & $10(18 \%)$ & $35(23 \%)$ & n.s. \\
\hline Less than 40 years old & $34(16 \%)$ & $10(18 \%)$ & $24(16 \%)$ & n.s. \\
\hline Less than 60 years old & $23(11 \%)$ & $2(4 \%)$ & $21(14 \%)$ & 0.009 \\
\hline Age does not matter & $86(42 \%)$ & $31(56 \%)$ & $55(36 \%)$ & 0.002 \\
\hline
\end{tabular}

$p$ value is presented to establish statistical significance between expert and non-expert treatment. n.s. not significant 
pathologies [17]. Magnetic resonance as a diagnostic test for meniscus damage was recommended by $97 \%$ of orthopaedists in this study. However, $50 \%$ of surgeons recommended ultrasound as a diagnostic method, which should not be practised according to the ESSKA meniscus consensus for traumatic or degenerative damage. Experts and non-experts should be educated on this.

Surgical expertise was significantly associated with the performance of the reconstructive procedures in comparison to diagnostic arthroscopy, which was performed more often by non-experts. Experts were significantly more likely to perform meniscus suture procedures than non-experts, as these procedures are considered advanced and challenging techniques. The clinical experience of participating in this survey of orthopaedists was correlated with the use of newly established methods. Experts were deciding to use bone marrow cells, biomaterials or autologous adipose tissue as meniscus repair methods. All of these approaches that involve the use of cells and biomaterial scaffolds have recently gained increasing attention as potential regenerative therapies in the field of musculoskeletal medicine [4]. Therefore, the observation that non-experts are less frequently choosing these options could be explained by their limited experience with new therapeutic options for patients, as they are still gaining experience with traditional meniscus treatment methods.

Non-expert surgeons were less likely to use objective physical tests, recommended a longer period from meniscus suture to full-range knee motion and admitted that patient age does matter for meniscus repair qualification. All of these issues might be correlated with less experience.

Both experts and non-experts preferred to suture traumatic meniscus tears in 18-year-old and 30-year-old football players. This proves the willingness of meniscus repair and awareness of its role in knee arthritis prevention.

An obvious strength of the study is that it was the first such developed survey study among Polish Arthroscopy Society members. This study had limitations. The questionnaire included 35 questions, which is a prominent number and could cause potential weariness and careless or ill-considered answers. However, during the pilot study, the average time for completion did not exceed $10 \mathrm{~min}$, and it would be difficult to collect detailed information about the postoperative aspects of care with fewer questions. Defining the level of expertise at a cut-off level of more than 100 arthroscopies performed per year could be considered a biased decision for this study. Further studies are required to demonstrate clinical comparisons or second-look arthroscopy outcomes.

\section{Conclusions}

The present survey provided useful recommendations for clinical decision-making regarding the management of knee arthroscopy. Agreement was found among almost all issues of meniscus tear treatment between experts and non-experts; however, the rehabilitation issues differed in both groups. Surgical expertise was associated with the performance of advanced meniscus repair techniques.

\section{Supplementary information}

Supplementary information accompanies this paper at https://doi.org/10. 1186/s12891-020-03649-9.

Additional file 1. A survey on orthopedists opinion for an arthroscopic treatment of meniscus injuries. A survey which was presented to orthopaedists. The questionnaire contains 35 questions regarding general arthroscopy and postoperative management

\section{Abbreviations}

AAT: Autologous adipose tissue; BMC: Bone marrow cells; EBM: Evidence Based Medicine; ESSKA: European Society for Sports Traumatology, Knee Surgery and Arthroscopy; LMW heparin: Low-molecular-weight heparine; MRI: Magnetic resonance imaging; PRP: Platelet rich plasma

\section{Acknowledgements}

The authors hereby want to thank all orthopedists who participated in this survey. A special gratitude goes out to Wojciech Lenartowski and Marcin Józefowski. RSQ Technologies company is acknowledged for help in preparing the survey.

\section{Authors' contributions}

PB conceived and designed the study. PB and TP participated in the setup of the study, participants recruitment, and data collection. KBŻ conducted the analysis. KBŻ drafted the first version of the manuscript. All authors helped in revising the manuscript and gave their final approval of the submitted version. All authors had full access to the data and take responsibility for the integrity of the data and the accuracy of the data analysis.

\section{Funding}

Not applicable.

\section{Availability of data and materials}

The datasets used during the current study are available from the corresponding author on reasonable request.

\section{Ethics approval and consent to participate}

According to the Bioethical Commitee of Karol Marcinkowski Medical University in Poznań, the consent of the bioethics commission is not required for "surveys involving the use of standardized surveys - used for their intended purpose, and the study will develop statistically selected elements of the survey" (ordinance No. 113/17 of the Rector of Karol Marcinkowski Medical University in Poznań, October 2nd, 2017).

Verbal informed consent was obtained from study participants before completing the survey (based on the opinion of Rehasport Clinic Scientific Council).

\section{Consent for publication}

Not applicable.

\section{Competing interests}

Not applicable.

\section{Author details}

'Department of Orthopedic Surgery, Rehasport Clinic, Górecka Street 30, 60201 Poznan, Poland. ${ }^{2}$ Institute of Bioorganic Chemistry Polish Academy of Sciences, Noskowkiego 12/14, 61-704 Poznań, Poland. ${ }^{3}$ Department of Spine 
Disorders and Pediatric Orthopedics, University of Medical Sciences Poznan, Poznan, Poland.

\section{Received: 8 June 2020 Accepted: 15 September 2020} Published online: 23 September 2020

\section{References}

1. Mitchell J, Graham W, Best TM, Collins C, Currie DW, Comstock RD, Flanigan DC. Epidemiology of meniscal injuries in US high school athletes between 2007 and 2013. Knee Surg Sports Traumatol Arthrosc. 2016;24(3):715-22.

2. Zhou T, Xu Y, Xu W. Emerging research trends and foci of studies on the meniscus: A bibliometric analysis. J Orthop Surg (Hong Kong). 2020;28(3): 2309499020947286. https://doi.org/10.1177/2309499020947286.

3. Makris EA, Hadidi P, Athanasiou KA. The knee meniscus: structure-function, pathophysiology, current repair techniques, and prospects for regeneration. Biomaterials. 2011;32(30):7411-31.

4. Shimomura K, Hamamoto S, Hart DA, Yoshikawa H, Nakamura N. Meniscal repair and regeneration: current strategies and future perspectives. J Clin Orthop Trauma. 2018;9(3):247-53.

5. Nawabi DH, Cro S, Hamid IP, Williams A. Return to play after lateral meniscectomy compared with medial meniscectomy in elite professional soccer players. Am J Sports Med. 2014;42(9):2193-8.

6. Poulsen E, Goncalves GH, Bricca A, Roos EM, Thorlund JB, Juhl CB. Knee osteoarthritis risk is increased 4-6 fold after knee injury-a systematic review and meta-analysis. Br J Sports Med. 2019;53(23):1454-63.

7. Stein T, Mehling AP, Welsch F, Von Eisenhart-Rothe R, Jäger A. Long-term outcome after arthroscopic meniscal repair versus arthroscopic partial meniscectomy for traumatic meniscal tears. Am J Sports Med. 2010;38(8): 1542-8

8. Karia M, Ghaly Y, Al-Hadithy N, Mordecai S, Gupte C. Current concepts in the techniques, indications and outcomes of meniscal repairs. Eur J Orthop Surg Traumatol. 2019;29(3):509-20. https://doi.org/10.1007/s00590-018-2317-5.

9. Vaquero-Picado A, Rodríguez-Merchán EC. Arthroscopic repair of the meniscus: surgical management and clinical outcomes. EFORT Open Rev. 2018;3(11):584-94. https://doi.org/10.1302/2058-5241.3.170059.

10. Patil SS, Shekhar A, Tapasvi SR. Meniscal preservation is important for the knee joint. Indian J Orthop. 2017;51(5):576-87. https://doi.org/10.4103/ortho. IJOrtho_247_17.

11. Xu C, Zhao J. A meta-analysis comparing meniscal repair with meniscectomy in the treatment of meniscal tears: the more meniscus, the better outcome? Knee Surg Sports Traumatol Arthrosc. 2015;23(1):164-70. https://doi.org/10.1007/s00167-013-2528-6.

12. Katano H, Koga H, Ozeki N, Otabe K, Mizuno M, Tomita M, et al. Trends in isolated meniscus repair and meniscectomy in Japan, 2011-2016. J Orthop Sci. 2018;23(4):676-81. https://doi.org/10.1016/j.jos.2018.04.003.

13. Doral MN, Bilge O, Huri G, Turhan E, Verdonk R. Modern treatment of meniscal tears. EFORT Open Rev. 2018;3(5):260-8. https://doi.org/10.1302/ 2058-5241.3.170067.

14. Pach M, Horáček F. Suture - the current trend of medial meniscus lesion treatment. Acta Chir Orthop Traumatol Cechoslov. 2018;85(1):62-9.

15. Ni J, Shi Z, Fan L, Guo N, Wang H, Dang X, Li D. The modified cross-suture technique for unilateral pulled-out anchor during all-inside meniscal repai BMC Musculoskelet Disord. 2020;21(1):480. https://doi.org/10.1186/s12891020-03502-z

16. Beaufils $P$, Becker R, Kopf $S$, Englund M, Verdonk R, Ollivier M, Seil R. Surgical management of degenerative meniscus lesions: the 2016 ESSKA meniscus consensus. Knee Surg Sports Traumatol Arthrosc. 2017;25(2):335-46.

17. Kopf S, Beaufils P, Hirschmann MT, Rotigliano N, Ollivier M, Pereira H, Becker R. Management of traumatic meniscus tears: the 2019 ESSKA meniscus consensus. Knee Surg Sports Traumatol Arthrosc. 2020;28(4):1177-94.

18. Amin NH, Hussain W, Ryan J, Morrison S, Miniaci A, Jones MH. Changes within clinical practice after a randomized controlled trial of knee arthroscopy for osteoarthritis. Orthop J Sports Med. 2017:5(4): 2325967117698439

19. Thorlund JB, Englund M, Christensen R, Nissen N, Pihl K, Jørgensen U, Lohmander LS. Patient reported outcomes in patients undergoing arthroscopic partial meniscectomy for traumatic or degenerative meniscal tears: comparative prospective cohort study. BMJ. 2017. https://doi.org/10. $1136 / \mathrm{bmj} . j 356$.

20. White PF. Outpatient anesthesia. In: Miller RD, editor. Anesthesia. 3rd ed. New York: Churchill-Livingstone; 1990. p. 2025-59.
21. Dahl V, Gierloff C, Omland E, Raeder JC. Spinal, epidural orpropofol anaesthesia for outpatient knee arthroscopy? Acta Anaesthesiol Scand. 1997; 41:1341-5.

22. Fanelli G, Sansone V, Nobili F, Pedotti E, Aldegheri G. Locoregional anesthesia for surgical arthroscopy of the knee. Minerva Anestesiol. 1992;58: $121-5$.

23. Fanelli G, Casati A, Garancini P, Torri G. Nerve stimulator and multiple injections technique for upper and lower limb blockade: failure rate, patient acceptance and neurologic complications. Anesth Analg. 1999;88:847-52.

24. Bordes P, Laboute E, Bertolotti A, Dalmay JF, Puig P, Trouve P, De Seze M. No beneficial effect of bracing after anterior cruciate ligament reconstruction in a cohort of 969 athletes followed in rehabilitation. Ann Phys Rehabil Med. 2017;60(4):230-6.

25. Yang XG, Feng JT, He X, Wang F, Hu YC. The effect of knee bracing on the knee function and stability following anterior cruciate ligament reconstruction: a systematic review and meta-analysis of randomized controlled trials. Orthop Traumatol Surg Res. 2019;105(6):1107-14.

26. Naik AA, Das B, Kamat YD. Avoid postoperative bracing to reduce ACL rerupture rates. Eur J Ortho Surg Traumatol. 2019;29(8):1743-7.

27. Drosos G, Stavropoulos N, Katsis A, Kesidis K, Kazakos K, Verettas DA. Postoperative pain after knee arthroscopy and related factors. Open Orthop J. 2008;2(1):110-4

28. Hirsh J, Levine MN. Low molecular weight heparin: laboratory properties and clinical evaluation. A review. Eur J Surg Suppl. 1994;571:9-22.

29. Kwong $L$. Therapeutic potential of rivaroxaban in the prevention of venous thromboembolism following hip and knee replacement surgery: a review of clinical trial data. Vasc Health Risk Manag. 2011;7(1):461.

30. Lu X, Lin J. Low molecular weight heparin versus other anti-thrombotic agents for prevention of venous thromboembolic events after total hip or total knee replacement surgery: a systematic review and meta-analysis. BMC Musculoskelet Disord. 2018;19(1):322.

31. Chmielewski D, Górecki A, Kusz D, Małdyk P, Marczyński W, Tomkowski W. Principles of prevention of venous thromboembolism in orthopedics and traumatology (updated on 02/18/2014). Ortop Traumatol Rehabil. 2014; 16(2):227-39. https://doi.org/10.5604/15093492.1105250.

32. Spang lii RC, Nasr MC, Mohamadi A, DeAngelis JP, Nazarian A, Ramappa AJ. Rehabilitation following meniscal repair: a systematic review. BMJ Open Sport Exerc Med. 2018;4(1):e000212. https://doi.org/10.1136/bmjsem-2016000212.

33. Bohl DD, Li J, Calkins TE, Darrith B, Edmiston TA, Nam D, Della Valle CJ. Physical therapy on postoperative day zero following total knee arthroplasty: a randomized, controlled trial of 394 patients. J Arthroplast. 2019;34(7):S173-7.

34. Haas R, Sarkies M, Bowles KA, O'Brien L, Haines T. Early commencement of physical therapy in the acute phase following elective lower limb arthroplasty produces favorable outcomes: a systematic review and metaanalysis examining allied health service models. Osteoarthr Cartil. 2016; 24(10):1667-81.

35. Yakkanti RR, Miller AJ, Smith LS, Feher AW, Mont MA, Malkani AL. Impact of early mobilization on length of stay after primary total knee arthroplasty. Ann Transl Med. 2019;7(4):69.

36. Arundale $A J H$, Kvist J, Hägglund $M$, Fältström A. Jumping performance based on duration of rehabilitation in female football players after anterior cruciate ligament reconstruction. Knee Surg Sports Traumatol Arthrosc. 2019;27(2):556-63.

37. Østerås H. Medical exercise therapy is effective after arthroscopic surgery of degenerative meniscus of the knee: a randomized controlled trial. J ClinMed Res. 2012;4(6):378-84.

38. Østerås H. A 12-week medical exercise therapy program leads to significant improvement inknee function after degenerative meniscectomy: a randomized controlled trial with one year follow-up. J Bodyw Mov Ther. 2014;18(3):374-82.

39. Østerås $H$, Østerås B, Torstensen TA. Is postoperative exercise therapy necessary in patients with degenerative meniscus? A randomized controlled trial with one year follow-up. Knee Surg Sports Traumatol Arthrosc. 2014; 22(1):200-6.

40. Nyland J. Is post-surgical rehabilitation sufficient? Would it be better to rehabituate? Knee Surg Sports Traumatol Arthrosc. 2018;26:2549-50.

41. Arıcan G, Özmeriç A, Şahin Ö, İltar S, Alemdaroğlu KB. Should we prefer magnetic resonance imaging to physical examination in meniscal tears. J Knee Surg. 2019. https://doi.org/10.1055/s-0039-1693449. 
42. Nacey NC, Geeslin MG, Miller GW, Pierce JL. Magnetic resonance imaging of the knee: an overview and update of conventional and state of the art imaging. J Magn Reson Imaging. 2017;45(5):1257-75.

43. Phelan N, Rowland P, Galvin R, O'Byrne JM. A systematic review and metaanalysis of the diagnostic accuracy of MRI for suspected ACL and meniscal tears of the knee. Knee Surg Sports Traumatol Arthrosc. 2016;24(5):1525-39.

\section{Publisher's Note}

Springer Nature remains neutral with regard to jurisdictional claims in published maps and institutional affiliations.

Ready to submit your research? Choose BMC and benefit from:

- fast, convenient online submission

- thorough peer review by experienced researchers in your field

- rapid publication on acceptance

- support for research data, including large and complex data types

- gold Open Access which fosters wider collaboration and increased citations

- maximum visibility for your research: over $100 \mathrm{M}$ website views per year

At $\mathrm{BMC}$, research is always in progress.

Learn more biomedcentral.com/submissions 